\title{
Continuous professional development in pathology: a continental view
}

\author{
Fred T Bosman
}

There is no self respecting professional who can do without continuous professional development (CPD). All of us know more that we did 10 years ago but we should also be aware of the fact that, relative to the explosive increase of knowledge, we are also ignorant of much more than we were 10 years ago. Pathologists who try to escape the pressure of CPD run the risk of lagging behind, of using outdated classifications, of being unable to diagnose "hot new entities," and of being confronted with revolting clinicians. Worse than that, the licensing boards might hunt them down and not renew their licence to practice. In urging CPD upon the pathology community, a positive supportive approach is bound to be easier to accept than uncomfortable pressure and the imposition of penalties. ${ }^{12}$ This might be the reason why some authorities have chosen the term continuous professional development rather than the more familiar "continuous medical education" (CME). A new euphemism that demands an explanation before one understands what it means is not an improvement, so I will stick to CME. This is justified by a search of published reports: a decent number of publications can be retrieved on CME but only few on CPD. ${ }^{3}$

The trend towards more and more strictly enforced CME is apparent in all European countries. Some are better organised than others but there is no "continental" country that has not instigated a CME enforcing system. It stands to reason that in a united Europe CME should be developed according to a consensus approach. This is clearly not (yet) the case. It is the purpose of this brief review to describe the current situation concerning CME in Europe, to analyse what is good and what is not so good about it, and to offer some reflections on how it could be developed further.

\section{Present situation in Europe}

The "continental" in the title of this paper is pretentious. It suggests that among European countries a generally supported concept has emerged concerning CME. This is clearly not the case. Continental western Europe includes about 15 countries that are all entirely autonomous regarding undergraduate and postgraduate medical education, licensing, specialty diplomas, and CME. The creation of the EU has undoubtedly contributed towards the development of a more common approach but individual countries have remained autonomous. This is in spite of the obligation of any member country to recognise the medical diplomas of any other member country as equivalent. It stands to reason that this fact alone has led to attempts to come to an integrated European approach. Initiatives taken in Europe in this domain have been mostly undertaken by the Union Européenne des Médecins Spécialistes (UEMS). This central board has specialty groups for all medical specialties recognised in the EU countries. Consequently, there is a pathology board, in which all member countries (not only those on the continent!) are represented. Up to now, the board has developed the European examination, an MCQ test assessing basic knowledge and morphological recognition skills that all practising pathologists should have at their disposal. The examination can only be taken by pathologists certified in one of the EU countries. The diploma does not replace national certification. How pathology trainees acquire their knowledge and skills is left entirely up to the specialty boards in the individual member countries. There is no commonly shared system of basic training requirements. There are no common rules for the accreditation of training institutions.

In spite of the absence of central regulation, several initiatives in Europe have resulted in CME programmes with a distinct European flavour. In these initiatives, the European Society of Pathology (ESP) has played a prominent role. Its biannual congresses (this year in Barcelona) have through the years been focused more on pathology practice development than on investigative pathology, with usually a plethora of slide seminars, workshops, and didactic seminars. Under the patronage of the ESP, the European School of Pathology has developed in Turin, offering strongly practice oriented courses for residents but attended also by certified pathologists. The ESP has also fostered research training in a diagnostic human pathology oriented setting in the annual EuroCellPath courses. The latter attempt to put together accomplished scientists, with a diagnostic as well as an investigative orientation, and pathology trainees with an $\mathrm{MD} / \mathrm{PhD}$ background. Graduate students as well as established investigators have participated and the limited size of the groups of participants has favoured intensive personal exchange.

A strong element in the offer of the CME activities in Europe is the programme organised by the various divisions of the International Academy of Pathology (IAP). The divisions are generally country oriented but it is not surprising that in the context of this international network of national activities there has been a strong tendency to "shop at the neighbours"- that is, there is significant international participation. There seems, however, not to be an urge towards European coordination of CME activities in an IAP context.

And then there are the national professional organisations. All of them place a relatively 
strong emphasis on CME. In the national societies that I have been involved with in the last two decades there has been a gradual shift from the programming of meetings on the basis of submitted papers towards didactic symposia, keynote lectures by acknowledged experts, and slide seminars. Attendance is usually limited to the national membership, although, for example, the German Society attracts attendance from all German speaking countries, and the meetings of the Pathological Society of Great Britain and Ireland also have some international flavour.

Apart from these more or less formalised CME efforts, there appear to be more regionally oriented efforts, informal but under appropriate conditions recognised for CME. These tend to be in a slide seminar format. Likewise (larger) pathology institutes will offer their own CME efforts. The regional and local events are clearly almost exclusively accessible for the happy few-those who know the "when, what, and where."

My overall impression is that in Europe we do not suffer from a lack of high quality CME activities. It is, however, extremely difficult to judge the situation adequately because of a lack of information: there is no freely accessible central European agenda that lists all CME activities, from the European down to the regional or even local level, with a brief description of content, format, how to register, and the credits offered.

\section{What characterises the available CME activities?}

As indicated above, the educational approach of the available CME activities is fairly standard. Didactic symposia correspond to conventional classroom teaching and they tend to summarise advances in factual knowledge rather than to fine tune problem solving skills. The same holds true for the expert keynote lectures. Slide seminars tend to be more oriented towards the development of problem solving skills, provided that the participants have been able to study the cases and express their personal opinion before the actual seminar. The seminars tend to be one man shows and less interactive than they might be, but on the whole they get reasonably close to practice oriented interactive problem solving skills training. Audit of CME activities will be necessary in order to attain the set goals. ${ }^{2}$

The potential for computer assisted learning, using local modules or what is available on the internet, is underutilised in Europe. The tide seems to be changing since the Pathology Interactive initiative taken by $\mathcal{F C P}{ }^{4}$ This concerns the release on CD-ROM of review articles with a CME goal, accompanied by relevant abstracts from published reports and sets of MCQ questions for automated self testing. There is much available on the internet, ${ }^{5-8}$ mostly developed in the USA (table 1), of variable but often excellent quality and rarely used systematically. This may be because a functioning system for accreditation of computer based CME modules or for crediting of participation, for example through the internet, has not been developed.
Table $1 \quad C M E$ websites

http ://path.upmc.edu/cme/

http ://www.afip.org/edu/cme/

http ://netcme.mdacc.tmc.edu

http ://www.medlib-med.utah.edu

http ://www.pathology.med.umich.edu

http ://med.virginia.edu/clinical/pathology/case studies

http ://www.slucare.edu/clinical/pathlab/case

http ://path.usuf2.usuhs.mi

\section{How are CME efforts accredited?}

This is a touchy issue. The by now universally applied approach is that of CME credit points. Participation in an accredited event offers a number of credit points and in order to remain licensed the pathologist must accumulate a minimum number of points over a set period of time. The choice of the package is left to the discretion of the individual. Attendance is honoured, rather than proven improvements in diagnostic skills or basic knowledge. This is clearly a less than satisfactory system. I might not be credited for a two hour in-depth discussion with a group of gastrointestinal pathologists (for example on the terrace of the venue of an international congress) on the merits of the currently used systems for classification of gastritis, but I will be for attending a lecture for an hour that might have been so somniferous that at the end I could not remember where I was, let alone what the lecture was about. For practical reasons registration of attendance may be the only functioning system for recognition of credits towards license renewal, but it is absolutely essential that systems are developed which credit the result and not the presence. ${ }^{9}$ This is, however, not only a European problem-CME officials worldwide struggle with it. Pathology Interactive offers a possibility for storage of MCQ scores, to be used in the future as evidence of self learning. Incidentally, there is no European approach towards credit recognition nor to number of credits required for license renewal. This is entirely the responsibility of the medical specialty boards of the individual countries.

\section{What's to come?}

The conditions for high quality postgraduate training in pathology have markedly improved over the last 20 years. Training programmes have been defined, accreditation requirements and procedures have been installed, and specialty examinations have become the rule, although a few European countries still do without them. To a certain extent UEMS efforts to develop a European view to this matter have played a positive role. Clearly, however, we are at the beginning of an evolution rather than at the end. The development of a European view on CME in pathology is lagging behind. In developing such a concept three domains should be considered: CME programming, the CME credit awarding system, and the structure of CME programmes.

CME PROGRAMMING

In the present situation, recertification is based partly upon accumulation of a sufficient number of CME credits. The choice of CME activities is left entirely up to the individual. I 
would favour a somewhat more structured approach. With a strong tendency towards subspecialty development in pathology, it would not be reasonable to prescribe standard CME programmes, without taking individual needs in the context of the profile of a particular position into account. However, a more systematic approach, leading to a balanced CME curriculum rather than a random collection of CME credits, seems to me entirely reasonable.

THE CME CREDIT AWARDING SYSTEM

Awarding of presence is clearly a poor way to award credits: this has nothing to do with attaining educational goals. A knowledge or skills test at the end of a CME effort would serve the purpose but is probably, as a general measure, somewhat exaggerated. A more general competence or skills test as part of the recertification procedure would be more appropriate and could easily replace CME credit counting: as long as a professional maintains the required knowledge and skills, it does not matter how. Examinations as part of the recertification procedure are, however, not (yet) seriously considered. An alternative solution could be proof of active participation in interactive CME modules. These could consist of interactive microscopy sessions but also working in computer based case oriented pathology training programmes. ${ }^{5-8}$ The latter might offer the CME student a performance score, useful for formative or for summative purposes. ${ }^{4}$ The European offer of computer based CME programmes is still very limited. I foresee, however, a rapid expansion in this domain. Fortunately the internet has no topographical boundaries and in principle any quality CME pathology module on the internet might be used by any potential CME student. The virtual classroom might largely replace the lecture hall in the coming years. This approach would allow a high level of flexibility in terms of choice and timing and might well become a main element in CME curricula.

THE STRUCTURE OF CME PROGRAMMES

As I have already argued above, a significant part of the currently available CME offer is knowledge oriented and requires no more than passive involvement of the CME student. To some extent, slide seminars imply active involvement but even that can be improved. I already argued in favour of interactive, case based CME pathology programmes, which test the participants' knowledge and observation and reasoning skills, and help to keep them at the required level. A variety of web sites offering such programmes is already available (table 1).

\section{What will Europe do?}

As yet, CME registration and recertification is strictly the domain of the medical specialty boards of the EU member countries. For the near future, I do not foresee a change here. In view of the recognition of medical specialty diplomas all over the EU, regardless of the EU country of origin, it would stand to reason that the European Board of Pathology issues CME requirements for European Board certified pathologists. Those are still limited in number but hopefully that will rapidly change and if so the CME issue becomes highly relevant.

What seems to be a perfectly logical first step is the exchange of information as to the available CME programmes and the coordination at a European level of the efforts towards developing new programmes. The ESP could play a key role in both. A web site functioning as a message board for posting CME programmes would be a rapidly attainable goal. Some level of peer review of the offered programmes might be necessary to guarantee an overall high quality. Registration for the events and CME credit registration could be managed through the site. Strong emphasis could be put on the creation of computerised cases in parallel with the CME events, to allow a maximum of CME students to profit from such an effort. The posted programmes need not necessarily be limited to international (European) events. Regional or national CME events might also benefit from international participation.

\section{Conclusions}

The issues raised in this paper can be summarised as follows:

- CME in pathology in Europe lacks in organisation, focus, and definition.

- CME in pathology lacks in educational dynamism. New (computer based) educational approaches need to be developed.

- The European Board of Pathology should formulate recertification CME requirements.

- The ESP should develop a CME policy and assume responsibility in providing information and coordination of the development of new CME programmes.

1 du Boulay C. Audit of continuing medical education for pathologists: strategies and implications. F Clin Pathol 1996;49:100-1.

$2 \mathrm{du}$ Boulay C. Continuing medical education for pathologists: an evaluation of the Royal College of Pathologists' Wessex pilot scheme. F Clin Pathol 1997;50:1022-6.

3 du Boulay C. Continuous professional development: some new perspectives. F Clin Pathol 1999;52:162-4.

4 Holzel H, van Diest P, Heard S. Continuing professional development: is the future "Pathology Interactive"? f Clin Pathol 1999;52:401-2.

5 Klatt EC, Dennis SE. Web-based pathology education. Arch Pathol Lab Med 1998;122:475-9.

6 Rashbass J. Why use the internet to teach pathology? 7 Clin Pathol 1998;51:179-82.

7 Horn KD, Sholehvar D, Nine J, et al. Continuing medical education on the World Wide Web (WWW). Interactive pathology case studies on the Internet. Arch Pathol Lab Med 1997;121:641-5.

8 Klatt EC. Web-based teaching in pathology. $\mathcal{F} A M A$ 1997;278:1787.

9 Conn RB. Can continuing medical education prepare the current practitioner for the 21st century? Arch Pathol Lab Med 1992;116:602-4. 